\title{
Estudo da influência da adição de cinzas de carvão mineral nas propriedades da cerâmica vermelha
}

\section{(Study of the influence of the addition of mineral coal ash on the properties of red ceramics)}

\author{
T. L. Zanin', W. Klitzke ${ }^{2}$, L. F. L. Luz Jr. ${ }^{3}$ \\ ${ }^{1}$ Departamento de Engenharia de Manutenção da Geração da Copel Geração e Transmissão S/A, R. José \\ Izidoro Biazetto 158, Bloco A, sala 223, Bairro Mossunguê, Curitiba, PR 81200-240 \\ ${ }^{2}$ Setor de Tecnologia da UFPR, R. Francisco H. Dos Santos s/n, Usinas Piloto de Tecnologia Química, Bloco A, \\ sala PO-09, Centro Politécnico, Bairro Jardim das Américas, Curitiba, PR 81530-990 \\ ${ }^{3}$ Departamento de Engenharia Química da UFPR, C.P. 19011, Ed. Administração, $1^{\circ}$ andar, DEQ/TC/UFPR. \\ Centro Politécnico, Bairro Jardim das Américas, Curitiba, PR 81530-990 \\ thiago.zanin@copel.com,wklitzke@ufpr.br,luzjr@ufpr.br
}

\begin{abstract}
Resumo
A adição de resíduos industriais em cerâmicas vermelhas tem sido o alvo de diversos estudos, onde se busca uma destinação final adequada ao resíduo e melhoria das características da cerâmica. Neste trabalho, avaliou-se a adição de cinzas leves de carvão mineral oriundas de uma usina termelétrica existente em Figueira, PR. Foram preparadas misturas de 0, 10, $20,30,40$ e 50\% de cinzas em argila e produzidos corpos de prova de $6 \mathrm{~cm}$ x $2 \mathrm{~cm}$ x $0,5 \mathrm{~cm}$ por calcinação a $950{ }^{\circ} \mathrm{C}$. Avaliou-se os parâmetros perda ao fogo, densidade aparente, porosidade aparente, retração linear, absorção de água e resistência mecânica. Os resultados dos ensaios indicaram que influência do material incombusto presentes nas cinzas foi superior a qualquer efeito dos outros componentes das cinzas.
\end{abstract}

Palavras-chave: cerâmica vermelha, cinzas de carvão mineral, resíduos industriais

\begin{abstract}
The addition of industrial waste into red ceramic has been the subject of several studies, which seek to dispose the waste properly and to improving the characteristics of ceramics. In this study, the addition of fly ash from coal derived from an existing power plant in Figueira, PR, Brazil, was evaluated. Mixtures of 0, 10, 20, 30, 40 and 50\% ash in clay were prepared and $2 \mathrm{~cm} \times 6 \mathrm{~cm} \times 0.5 \mathrm{~cm}$ samples produced by calcination at $950{ }^{\circ} \mathrm{C}$. The loss on ignition, bulk density, apparent porosity, linear shrinkage, water absorption and mechanical strength parameters were evaluated. The results indicated that the influence of unburned material present in the ash was higher than any effect of other components of the ash
\end{abstract}

Keywords: red ceramic, mineral coal ashes, industrial wastes.

\section{INTRODUÇÃO}

O despertar da questão ambiental levantou uma grande preocupação com o destino dos resíduos sólidos, para os quais o simples destino para aterros não é mais aceita como solução definitiva. Uma rota pesquisada atualmente é a incorporação dos resíduos em materiais de construção civil, como concretos e cerâmicas. Um resíduo gerado em grandes quantidades, principalmente no sul do Brasil são as cinzas de carvão mineral, as quais atualmente são aterradas ou usadas em concretos [1]. Um destino possível para estas cinzas é a sua utilização em cerâmicas vermelhas [2], como tijolos, onde a cinza poderá contribuir com redução de densidade, modificações na absorção de água e de propriedades mecânicas [3]. A adição de outros resíduos industriais em cerâmicas vermelhas foi alvo de diversos estudos [4-6] sendo que todos concluíram a viabilidade técnica.

\section{MATERIAIS E MÉTODOS}

Foi utilizada argila proveniente de Lapa, município da região metropolitana de Curitiba (folheto de Mariental) e as cinzas de carvão mineral retidas no filtro de mangas da Usina Termelétrica de Figueira, PR. A argila foi seca em estufa a $100{ }^{\circ} \mathrm{C}$ e moída em moinho de bolas até que todo o material não ficasse retido na peneira 60 mesh (abertura $0,25 \mathrm{~mm}$ ). As cinzas foram utilizadas exatamente na forma com que saíram do processo termoelétrico, portanto não foi realizado nenhum processo de preparação, como moagem, classificação, secagem ou outros. As características químicas das cinzas de diversas termoelétricas brasileiras foram estudadas [7]. Em cápsula de porcelana os materiais foram misturados e 
homogeneizados manualmente nas seguintes proporções mássicas de argila e cinzas, respectivamente: 100/0, 90/10, 80/20, 70/30, 40/60 e 50/50. Para cada composição foram prensados nove corpos de prova [8], nas dimensões de $6,0 \mathrm{~cm}$ x $2,0 \mathrm{~cm} \times 0,5 \mathrm{~cm}$, sendo que a massa inicial de cada corpo de prova foi $11 \mathrm{~g}$ e na conformação utilizou-se uma prensa manual uniaxial sob $200 \mathrm{kgf} / \mathrm{cm}^{2}$, conforme a metodologia estabelecida [9]. A secagem dos corpos de prova ocorreu em estufa Heraeus a $100{ }^{\circ} \mathrm{C} / 12 \mathrm{~h}$ e a queima em forno elétrico (Linn Electro Therm) por meio da seguinte curva de queima: no início, com velocidade de aquecimento $2,8^{\circ} \mathrm{C} / \mathrm{min}$ até $540{ }^{\circ} \mathrm{C}$ e aumentou-se a velocidade de aquecimento para $10{ }^{\circ} \mathrm{C} / \mathrm{min}$ até o patamar máximo $950{ }^{\circ} \mathrm{C} / 3 \mathrm{~h}$, evitandose assim a formação do "coração negro", sendo resfriado naturalmente até temperatura ambiente [4]. Os parâmetros perda ao fogo, densidade aparente, porosidade aparente, retração linear e absorção de água foram determinados [9]. Os ensaios de resistência mecânica foram realizados e os resultados calculados conforme descrito no anexo C da NBR 13818 [10], com a máquina de ensaio EMIC.

\section{RESULTADOS E DISCUSSÃO}

$\mathrm{Na}$ análise dos dados obtidos, inicialmente aplicouse o teste de Dixon, eliminando os corpos de prova que apresentaram qualquer parâmetro com probabilidade de inconsistência em relação aos outros $>5 \%$. Com este critério, foi eliminado um total de onze corpos de prova, sendo de um a três corpos por grupo de composição. Destaca-se que cada corpo de prova eliminado foi removido de todos os parâmetros, não apenas do parâmetro que apresentou alta variância.

Tabela I - Aproveitamento dos corpos de prova. [Table I - Utilization of samples.]

\begin{tabular}{ccc}
\hline $\begin{array}{c}\text { Composição } \\
\text { \% de cinzas) }\end{array}$ & $\begin{array}{c}\text { Corpos de prova } \\
\text { válidos }\end{array}$ & $\begin{array}{c}\text { Corpos de prova } \\
\text { eliminados }\end{array}$ \\
\hline 0 & 8 & 1 \\
10 & 8 & 1 \\
20 & 8 & 1 \\
30 & 7 & 2 \\
40 & 6 & 3 \\
50 & 6 & 3 \\
\hline
\end{tabular}

A seguir são apresentados os valores obtidos e uma breve análise dos mesmos. Para comparação, foi aplicado o teste $\mathrm{t}$ de student, o qual indicou que existe mais de $95,0 \%$ de certeza que os valores de cada composição são diferentes, exceto quando indicado no texto.

Em uma avaliação rápida seria esperado que a perda ao fogo reduzisse com a elevação da fração de cinzas no corpo de prova, pelo fato das mesmas já terem sofrido a calcinação na caldeira da termelétrica. Porém os resultados da perda ao fogo foram diferentes do esperado, mas são justificados pela presença de material incombusto nas cinzas, o qual é transformado principalmente em dióxido de carbono durante
Tabela II - Valores de Perda ao Fogo (em porcentagem). [Table II - Values of Fire Loss (percentage).]

\begin{tabular}{ccc}
\hline $\begin{array}{c}\text { Composição } \\
\text { (\% de cinzas) }\end{array}$ & $\begin{array}{c}\text { Média } \\
(\%)\end{array}$ & Desvio Padrão \\
\hline 0 & 12,17 & 0,098 \\
10 & 12,60 & 0,0652 \\
20 & 13,352 & 0,0752 \\
30 & 14,13 & 0,0916 \\
40 & 14,80 & 0,1419 \\
50 & 15,74 & 0,1697 \\
\hline
\end{tabular}

Tabela III - Valores de retração linear (em porcentagem do comprimento).

[Table III - Values of linear shrinkage (in percent of length).]

\begin{tabular}{ccc}
\hline $\begin{array}{c}\text { Composição } \\
\text { \% de cinzas })\end{array}$ & Média $(\%)$ & Desvio Padrão \\
\hline 0 & 1,88 & 0,0912 \\
10 & 1,97 & 0,0890 \\
20 & 2,19 & 0,0589 \\
30 & 2,50 & $0,0000\left(^{*}\right)$ \\
40 & 2,53 & 0,1254 \\
50 & 2,94 & 0,0860 \\
\hline
\end{tabular}

OBS: (*) Os valores medidos de todos os corpos de prova foram iguais.

a calcinação do material e sai na forma de gás. A presença do incombusto é detectada visualmente pela coloração escura das cinzas.

Observou-se uma tendência de elevação da retração linear acompanhando o teor de cinzas. Nesta análise, o teste $\mathrm{t}$ de student indicou que não existe certeza que os valores de $10 \%$ e $20 \%$ sejam diferentes, assim como os valores de $30 \%$ e $40 \%$. Também foi possível identificar que os valores de $40 \%$ e $50 \%$ são estatisticamente iguais. Qualitativamente, principalmente avaliando-se os valores de $0 \%, 30 \%$ e $50 \%$, pode-se detectar que a adição de cinzas eleva a retração linear e quanto maior a proporção de cinzas, maior a retração. Porém, para elaboração de um modelo matemático, é necessário um novo levantamento de dados, preferencialmente com uso de instrumentos melhores que o paquímetro disponível no estudo, o qual possuía resolução de $0,1 \mathrm{~mm}$.

A porosidade aparente aumenta com o aumento da fração mássica de cinzas, comportamento também observado na absorção de água, enquanto a densidade aparente decresce. Todos estes fatos são explicados pela presença de matéria incombusta nas cinzas, e este fato predomina sobre qualquer influência do silício e metais existentes na cinza.

Os resultados do teste de rompimento demonstram que a adição de cinzas provoca uma perda da resistência mecânica na argila, sendo este efeito minimizado quando maiores proporções de cinzas são adicionadas. Porém, a análise estatística dos dados mostram dois impedimentos para o 
Tabela IV - Resultados do teste $\mathrm{t}$ de student para os valores de retração linear (probabilidade dos valores serem estatisticamente iguais).

[Table IV - Results of Student t test for linear shrinkage values (probability values are statistically equal).]

\begin{tabular}{cccccc}
\hline Composição & 0 & 10 & 20 & 30 & 40 \\
\hline 10 & 0,35062 & & & & \\
20 & 0,00009 & 0,00024 & & & \\
30 & 0,00000 & 0,00000 & 0,00000 & & \\
40 & 0,00000 & 0,00149 & 0,00057 & 1,00000 & \\
50 & 0,00000 & 0,00008 & 0,00006 & 0,00006 & 0,00290 \\
\hline
\end{tabular}

Tabela V - Valores de densidade aparente $\left(\mathrm{em} \mathrm{g} / \mathrm{cm}^{3}\right)$. [Table $V$ - Values of density $\left(\right.$ in $\left.\mathrm{g} / \mathrm{cm}^{3}\right)$.]

\begin{tabular}{ccc}
\hline $\begin{array}{c}\text { Composição } \\
\text { (\% de cinzas) }\end{array}$ & Média & $\begin{array}{l}\text { Desvio } \\
\text { Padrão }\end{array}$ \\
\hline 0 & 1,55 & 0,0247 \\
10 & 1,47 & 0,0108 \\
20 & 1,43 & 0,0215 \\
30 & 1,38 & 0,0092 \\
40 & 1,31 & 0,0133 \\
50 & 1,25 & 0,0040 \\
\hline
\end{tabular}

Tabela VI - Valores de absorção de água (em percentual da massa do corpo de prova).

[Tabela VI - Values of water absorption (percentage of body mass of samples).]

\begin{tabular}{ccc}
\hline $\begin{array}{c}\text { Composição } \\
\text { (\% de cinzas) }\end{array}$ & $\begin{array}{c}\text { Média } \\
(\%)\end{array}$ & $\begin{array}{c}\text { Desvio } \\
\text { Padrão }\end{array}$ \\
\hline 0 & 24,12 & 0,2095 \\
10 & 27,80 & 0,1753 \\
20 & 29,92 & 0,3012 \\
30 & 31,76 & 0,3785 \\
40 & 34,35 & 0,2589 \\
50 & 37,66 & 0,1117 \\
\hline
\end{tabular}

Tabela VII - Valores de porosidade aparente (em percentual). [Tabela VII - Values of apparent porosity (in percentage).]

\begin{tabular}{ccc}
\hline $\begin{array}{c}\text { Composição } \\
\text { (\% de cinzas) }\end{array}$ & Média & $\begin{array}{c}\text { Desvio } \\
\text { Padrão }\end{array}$ \\
\hline 0 & 37,06 & 0,2731 \\
10 & 43,10 & 0,2426 \\
20 & 47,19 & 0,4606 \\
30 & 50,58 & 0,6277 \\
40 & 55,14 & 0,3949 \\
50 & 61,24 & 0,2715 \\
\hline
\end{tabular}

Tabela VIII - Valores de rompimento (em quilograma-força por centímetro quadrado).

[Table VIII - Values of rupture (in kilograms-force per square centimeter).]

\begin{tabular}{ccc}
\hline $\begin{array}{c}\text { Composição } \\
\text { (\% de cinzas) }\end{array}$ & Média & $\begin{array}{l}\text { Desvio } \\
\text { Padrão }\end{array}$ \\
\hline 0 & 10,33 & 1,5028 \\
10 & 6,83 & 1,6507 \\
20 & 6,83 & 1,3460 \\
30 & 8,70 & 0,7362 \\
40 & 8,32 & 0,1722 \\
50 & 8,52 & 0,1520 \\
\hline
\end{tabular}

Tabela IX - Resultados do teste $\mathrm{t}$ de student para os valores de rompimento (Probabilidade dos valores serem estatisticamente iguais).

[Table IX - Results of Student $t$ test for values of rupture (Probability values are statistically equal).]

\begin{tabular}{cccccc}
\hline Fração mássica de cinzas & $0 \%$ & $10 \%$ & $20 \%$ & $30 \%$ & $40 \%$ \\
\hline $10 \%$ & 0,0078 & $\mathrm{x}$ & $\mathrm{x}$ & $\mathrm{x}$ & $\mathrm{x}$ \\
$20 \%$ & 0,0012 & 0,9056 & $\mathrm{x}$ & $\mathrm{x}$ & $\mathrm{x}$ \\
$30 \%$ & 0,0231 & 0,0662 & 0,0293 & $\mathrm{x}$ & $\mathrm{x}$ \\
$40 \%$ & 0,0034 & 0,2019 & 0,0093 & 0,1169 & $\mathrm{x}$ \\
$50 \%$ & 0,0114 & 0,1936 & 0,0307 & 0,0307 & 0,0775 \\
\hline
\end{tabular}

uso dos resultados, os quais podem invalidar as conclusões sobre resistência mecânica. Inicialmente pode-se verificar o alto desvio padrão dos valores, principalmente nos casos de 0,10 e $20 \%$, que tornam os resultados pouco confiáveis. Realizando o teste $\mathrm{t}$ de student para os resultados, obtemos as probabilidades apresentadas na Tabela IX. 
Conforme mostrado na Tabela IX, seis das quinze combinações não apresentam certeza acima de $95 \%$ quanto a igualdade ou diferença dos resultados, invalidando estas comparações. O único fato que pode ser afirmado é de que a adição de cinzas reduz a resistência mecânica, porém não é correto realizar avaliações quanto aos efeitos de diferentes frações mássicas de cinzas na cerâmica.

\section{CONCLUSÕES}

Com os resultados apresentados, pode-se concluir que a adição das cinzas geraram efeitos comparáveis com a adição de matéria orgânica, sendo o único benefício da adição das cinzas de carvão mineral na cerâmica vermelha a imobilização e uso do resíduo, não acarretando nenhum ganho para a cerâmica. Recomenda-se que novos estudos sejam realizados com cinzas calcinadas, para viabilizar a avaliação dos efeitos da cinza, sem a interferência do incombusto. Também se sugere que seja avaliada a quantidade de incombusto nas cinzas e realizados os ensaios com uma quantidade de matéria orgânica equivalente à matéria incombusta para validar a indicação dos estudos apresentados.

\section{REFERENCIAS}

[1] E. A. Oliveira, Perspectivas da geração termelétrica a carvão no Brasil no horizonte 2010-2030, Diss. Mestrado, COPPE, UFRJ, RJ (2009).

[2] K. Komnitas, D. Zaharaki, Mineral Eng. 20 (2007)
1261-1277

[3] M. Aineto, A. Acosta, I. Iglesias, The role of a coal gasification fly ash as clay additive in building ceramic, $\mathrm{J}$. Eur. Ceram. Soc. 25 (2005) 3783-3787

[4] W. Klitzke, Influência da adição de lodo de indústria papeleira na produção de cerâmica vermelha, monografia de conclusão de curso, UFPR (2009).

[5] N. Campregher, Estudo de viabilidade da incorporação do lodo da estação de tratamento de efluentes da indústria de papel, celulose e aparas em material cerâmico, 2005. Disponível em $<$ http://www.tede.ufsc.br/teses/ PENQ0173. pdf $>$, acesso em 12/03/2009.

[6] E. L. Bigélli, Obtenção de vitrocerâmicos sinterizados a partir da combinação de escórias siderúrgicas e cinzas volantes, Diss. Mestrado, Engenharia e Ciência dos Materiais, UFPR, Curitiba, PR (2005).

[7] F. S. Depoi, D. Pozebon, W. D. Kalkreuth, Cheminal characterization offeed colas and combustion-by-products from Brazilian power plants, Int. J. Coal Geology $\mathbf{7 8}$ (2008) 227-236

[8] N. S. Gomes, Comentários sobre medidas da dispersão e sua influência no cálculo e no controle tecnológico da alvenaria estrutural, 2005. Disponível em < http://www. anicer.com.br/index.asp?pg=artigos. asp\&idartigo $=1,>$, Acesso 23/11/2010.

[9] P. S. Santos, Ciência e Tecnologia de Argilas, $2^{\text {a }}$ Ed., Vol. 1, Edgard Blücher, S. Paulo, SP (1992) 178.

[10] ABNT, Associação Brasileira de Normas Técnicas, "Blocos cerâmicos para alvenaria, especificação: NBR 13818 /1997", anexo C.

(Rec.06/04/2011, Rev. 14/04/2012, Ac. 29/07/2012) 